\title{
Assessing the Vulnerability of Agricultural Production Activities in the Coastal Area of Thua Thien Hue Province, Vietnam by GIS Analysis Tools
}

\author{
Nguyen Hoang Son', Dao Dinh Cham ${ }^{2,3}$, Phan Anh Hang', Nguyen Trong Quan1, \\ Nguyen Thanh Hoan ${ }^{2,3}$ \\ ${ }^{1}$ University of Education, Hue University, Hue, Vietnam \\ ${ }^{2}$ Institute of Geography, Vietnam Academy of Science and Technology, Hanoi, Vietnam \\ ${ }^{3}$ Graduate University of Science and Technology, Vietnam Academy of Science and Technology, Hanoi, Vietnam \\ ${ }^{4}$ University of Science, Hue University, Hue, Vietnam \\ Email: hoanrs@gmail.com
}

How to cite this paper: Son, N. H., Cham, D. D., Hang, P. A., Quan, N. T., \& Hoan, N. T. (2019). Assessing the Vulnerability of Agricultural Production Activities in the Coastal Area of Thua Thien Hue Province, Vietnam by GIS Analysis Tools. Journal of Geoscience and Environment Protection, 7, 116-130.

https://doi.org/10.4236/gep.2019.75012

Received: March 31, 2019

Accepted: May 24, 2019

Published: May 27, 2019

\section{Copyright $\odot 2019$ by author(s) and} Scientific Research Publishing Inc. This work is licensed under the Creative Commons Attribution International License (CC BY 4.0).

http://creativecommons.org/licenses/by/4.0/

\section{cc) (i) Open Access}

\begin{abstract}
Using Geography Information System (GIS) tools and remote sensing data in assessing the level of vulnerability of agricultural production activities in the coastal area has become more efficient in the recent years. This research has identified the sensitivity index (S) (including the traffic access index; the impact of residential areas; the impacts of industrial zones; the community dependence level), exposure index (E) (the sea level rises to 2100; the temperature change to 2100), the adaptable capacity index (AC) (slope; morphology), thereby synthesizing the vulnerability index $(\mathrm{V})$. Based on the indexes to calculate vulnerability, the high to very high vulnerability area is $37,081.44$ ha, accounting for $68.09 \%$; the average vulnerability level is $15,286.49$ ha, accounting for $28.07 \%$; the low to very low vulnerability level with an area is 2087.82 ha, accounting for $3.84 \%$ of the total area. With a high and very high vulnerability accounting for $68.09 \%$, there will be great influences on the lives of resident in the area, especially agricultural production.
\end{abstract}

\section{Keywords}

Vulnerability Indexes, GIS Tools, Agricultural Production Activity, Coastal Areas

\section{Introduction}

From the 40s of the twentieth century, Gillbert F. White and the research group 
were pioneers of research related to vulnerabilities caused by disasters for society. Subsequently, this issue has been studied by many authors, such as White \& Haas, 1975; O’Keefe et al., 1976; Zimmerer \& Bassett, 2003; Forsyth, 2004; Peet \& Watts, 2004; Walton et al., 2008. The theoretical advance is found in the book “Dangerous Shore" (Blaikie et al., 1994; Cutter, 1996; Turner et al., 2003; Wisner et al., 2004) especially the models development of the pressure and the liberation. For more than a decade, there have been many different assessment approaches to assess vulnerability implemented and there are many assessment and comparison reports such as a handbook on vulnerabilities of current generation and next generation and the vulnerable assessment tools (Carg et al., 2007); assessment of vulnerability: summary report on methods and tools for impact assessment, vulnerability and capacity to adapt to climate change (UNFCCC, 2008); overview of methods and tools for adapting to climate change (Schipper et al., 2010); an overview of approaches (Morgan, 2011); summary report on vulnerability caused by climate change and impact assessment tools (Balangue, 2013); guidelines for assessing vulnerability, impact and capacity to adapt to climate change (Provia, 2013). The report summarizes the tools and methodologies for assessing vulnerability and adaptive capacity to climate change (Rizvi et al., 2014).

Recent vulnerability assessment reports conducted in Southeast Asia are a good example. These reports focus mainly on flooded areas in the lower Mekong region (ICEM, 2015). The report assesses the ranking of vulnerabilities in some provinces to identify the most vulnerable provinces in the lower Mekong Delta (USAID, 2013); a Mekong tributary (WWF, 2013b); a simple ecosystem like Ramsar wetland (Meynell et al., 2014), or urban center (ICEM, 2015); assessing the vulnerability of the aquaculture sector in Vietnam to climate change (World Bank, 2010). IPCC climate change vulnerability studies have identified seven important factors when assessing vulnerability (IPCC, 2007); Vulnerability index is built on 4 parameters: 1 . Condition (E); 2. Sensitivity (S); 3. Potential impacts (PI); 4. Adaptive capacity (AC) (Allison et al., 2009).

In Vietnam, climate change has been studied a lot after Vietnam joined the signing of the United Nations Framework Convention Climate Change (UNFCCC) in 1992 and then joined the Kyoto Protocol in 1998. Many Vietnamese scientists have studied climate change in depth as Nguyen Duc Ngu with the advent of the book Climate Change (Ngu, 2008). The Ministry of Natural Resources and Environment is Vietnamese government unit that presides over activities related to climate change. Until now, the Ministry of Natural Resources and Environment has developed three scenarios of climate change and the sea level rise for Vietnam in turn published in 2009, 2012 and 2016 (MONRE, 2009, 2012, 2016).

During the period 1994-1996, Tom et al. (1996) studied the overall vulnerable ability of the coastal zone of Vietnam due to sea level rise and climate change. From 2001 to 2005, the study and assessment of vulnerability of coastal areas in South Central Vietnam as a scientific basis for mitigating disasters and sustainable land use planning was carried out in the period of 2001-2002 (Nhuan, 2002) 
or a project to investigate and evaluate the vulnerability of resources-environment and marine meteorological conditions of Viet Nam; forecasting natural disasters and environmental pollution in coastal areas and has developed a map of vulnerability maps for the entire coastal area of Vietnam including regions: North, Central, Southwest, South, Islands Truong Sa until 2015, 2020 and the scenario of sea level rise of $0.5 \mathrm{~m}$ and $1 \mathrm{~m}$ (Nhuan, 2011). Building flood vulnerability assessment methods in Central Vietnam based on the use of questionnaires and surveys of people in the study area (Son \& Van, 2012). World Wide Fund for Nature (WWF) has conducted a research project: the project "Rapid assessment of vulnerability synthesis and adaptability to climate change in three coastal districts, Ben Tre province" (WWF, 2012) and the project "Assessing the level of vulnerability to climate change of ecosystems in Vietnam" (WWF, 2013a). However, to coastal areas in Thua Thien Hue province, there are no works evaluating the vulnerability level to agricultural production under the impact of climate change.

The coastal area of Thua Thien Hue province has 5 districts, accounting for $52 \%$ of the natural area of the whole province, with a coastline of $120 \mathrm{~km}$. This is a region with a variety of natural resources such as ecological systems, coral reefs, mineral resources... At the same time, it is also a region with many cultural historical heritages and unique architecture where there are many strong economic development activities such as seafood capture and processing, trade, transport, urbanization... However, the current socio-economic development in these regions is not really durable because people's livelihood depends mainly on natural resources; the main production activity of the people is agricultural production. Drought situation and the lack of freshwater severely prolonged in the dry season; floods are increasingly fierce during the rainy season. The rapid development of urbanization, industrialization and aquaculture has caused damage to natural resources, the environment and the livelihoods of the coastal people. To improve the lives of people; at the same time finding a new direction for sustainable socio-economic development and improve the quality of life for people in the face of the effects of climate change in general and particular natural disasters, there should be measures to adapt to the climate change, limiting the effects of natural disasters. Therefore, the assessment of the vulnerability due to climate change impacts on agricultural production activity in coastal areas of Thua Thien Hue province is an important basis for proposing solutions.

\section{Study Area}

Figure 1 shows location of the study area in Vietnam map (a red rectangle in the upper left map), in provincial level (red color in the lower left map) and coastal agriculture area (yellow parts in the right map). The coastal area of Thua Thien Hue province include 27 communes in Phong Dien districts (Phong Chuong, Phong Binh, Dien Huong, Dien Mon and Dien Hoa communes), Quang Dien district (Quang An and Quang Thanh, Quang Phuoc, Quang Cong, Quang Ngan, Quang Thai, Quang Loi communes), Phu Vang district (Vinh Phu, Vinh 


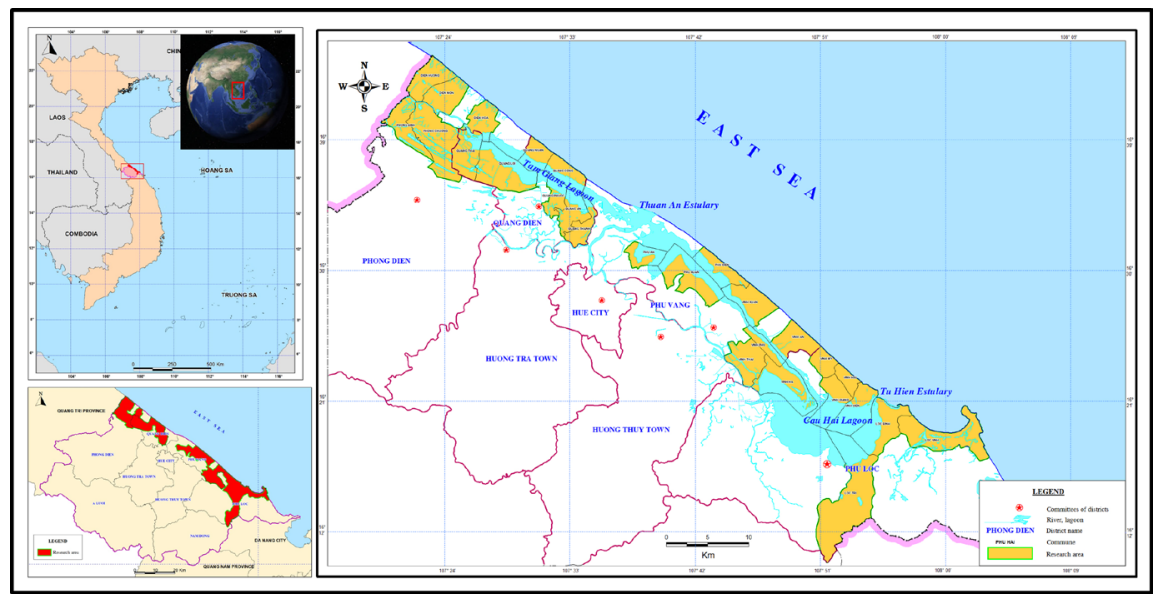

Figure 1. Map of location of the study area.

Ha, Phu Xuan, Vinh Thai, Vinh Xuan, Phu Dien, Vinh An, Phu An communes), Phu Loc district (Loc Binh, Vinh Hai, Vinh My, Vinh Giang, Loc Tri, Vinh Hien and Loc Vinh communes). This is an area of 54,455.75 ha, accounting for $10.82 \%$ of the province's natural area (Thua Thien Hue province: 503.320 ha). The total population in the coastal area is 213,547 people, accounting for $18.5 \%$ of Thua Thien Hue's population; Population density is 514.2 people $/ \mathrm{km}^{2}, 2.24$ times higher than the population density of the province $\left(230\right.$ people $\left./ \mathrm{km}^{2}\right)$ (Thua Thien Hue Statistical Office, 2017).

The coastal area of Thua Thien Hue province is located in the coastal plain. This is a narrow land strip running along National Highway 49B. The coastal area of Thua Thien Hue province is typical for abration, accumulation, and sand dunes plain. The plain does not form a continuous band but occasionally breaks due to the protruding branches or hills. Absolute heights of $20 \mathrm{~m}$ or less, including 3 types of the terrain: accumulation plains, lagoons and coastal sand dunes.

\section{Study Method}

\subsection{Implementation Process}

Standardize statistical data: Use inherited statistics obtained from data of relevant industries, then quantify and use the calculation formula to standardize the index from 0 - 100.

Spatial analysis: Using spatial analysis tools in GIS to build variables serving for analysis and evaluation.

Integrating information and multiplying weighted information classes: Using indexed variables that have standardized values of $0-100$ using algorithms to synthesize and calculate key indexes and indices extra.

\subsection{Method of Standardizing Variables and Synthesizing Indicators}

\subsubsection{Build and Standardize Variables}

The variables in the vulnerability assessment are determined basing on the im- 
pacts, impacts of nature and socio-economy. Key indicators are determined basing on the IPCC's theoretical point of view and applied by many scientists in the assessment. Variables to use in evaluation are (Table 1).

Value variables are understood as a quantity that is included in the formula to calculate for a value to be searched. The selection of variables to assess vulnerability depends on the theory and the approach method combined with the expert opinion. Different variations will give different results.

For each variable, due to measured by different quantities (for example, the temperature variable is measured in degrees Celsius, the influence level; or the AC index is measured by socio-economic factors). Therefore, in order to be able to evaluate, we have to put quantities into one axis (the same unit). The unit here is the evaluation index. Therefore, we apply the following formula (World Wide Fund for Nature, WWF, 2013a):

$$
\text { Index }=\frac{X-X_{\min }}{X_{\text {max }}-X_{\min }} \times 100
$$

Table 1. Variables used in vulnerability assessment.

\begin{tabular}{|c|c|c|c|c|}
\hline Main index & Sub-index & Meaning & Document source & $\begin{array}{l}\text { The formula } \\
\text { applies to } \\
\text { standardization }\end{array}$ \\
\hline \multirow[b]{3}{*}{ Sensitive (S) } & Traffic access index & $\begin{array}{l}\text { The closer to the transport system this indicator is, } \\
\text { the more sensitive the agricultural production is }\end{array}$ & Space analysis & (2) \\
\hline & $\begin{array}{l}\text { Influence of residential } \\
\text { areas }\end{array}$ & $\begin{array}{l}\text { Determination index: the closer to the urban } \\
\text { population area is, the more sensitive agricultural } \\
\text { production activities are }\end{array}$ & Space analysis & (2) \\
\hline & $\begin{array}{l}\text { Influence of industrial } \\
\text { zones }\end{array}$ & $\begin{array}{l}\text { Expressing the sensitivity level of agricultural } \\
\text { production activities to the development of } \\
\text { industrial zones (The closer to industrial zones, the } \\
\text { more sensitive the index is) }\end{array}$ & Space analysis & (2) \\
\hline \multirow[t]{2}{*}{ Exposure (E) } & Sea levels rise to 2100 & $\begin{array}{l}\text { Determine the level of the impact of sea level rising } \\
\text { on agricultural production activities }\end{array}$ & $\begin{array}{l}\text { Sea level rise scenario to } 2050 \text { (based } \\
\text { on climate change scenario of } \\
\text { Ministry of Natural Resources and } \\
\text { Environment) - DEM elevation } \\
\text { mode }\end{array}$ & (1) \\
\hline & $\begin{array}{l}\text { Temperature change to } \\
\qquad 2100\end{array}$ & $\begin{array}{l}\text { Determine the temperature's impact level on } \\
\text { agricultural production activities }\end{array}$ & $\begin{array}{l}\text { Scenario of temperature change to } \\
2050 \text { (based on climate change } \\
\text { scenario of Ministry of Natural } \\
\text { Resources and Environment) }\end{array}$ & (1) \\
\hline $\begin{array}{l}\text { Adaptive } \\
\text { Capacity }\end{array}$ & Shape & $\begin{array}{l}\text { The agricultural production activity has a long and } \\
\text { fragmented structure, which is less adaptable } \\
\text { ability than the centralized areas }\end{array}$ & $\begin{array}{l}\text { Analysis from the distribution map } \\
\text { of ecosystems in coastal areas of } \\
\text { Thua Thien Hue province }\end{array}$ & (1) \\
\hline
\end{tabular}




$$
\text { Index }=100-\left(\frac{X-X_{\text {min }}}{X_{\text {max }}-X_{\text {min }}}\right) \times 100
$$

In which: $X$ is the value.

$X_{\min }$ : The smallest value.

$X_{\max }$ : The greatest value.

For the variables show as low as possible, apply the formula (1) to standardize, whereas, with the higher variables as possible, the formula (2) is applied to standardize the indicators.

\subsubsection{Variables of Sensitive Index (S) (Sensitivity)}

- Traffic access index: Sensitive index of agricultural production activity for traffic roads is built from the separation of traffic road information of terrain maps. Calculating the distance with the maximum value of $10 \mathrm{~km}$, the meaning of this indicator indicates the closer to the road the agricultural production activities are, the more sensitive and vulnerable they are.

- Impact of residential areas: The sensitivity index to agricultural production activities for residential areas is built from the separation of residential and urban information layers of class status maps, then calculating the distance with the largest value of $15 \mathrm{~km}$, the meaning of this indicator indicates that agricultural production activities which are close to residential areas are more sensitive and vulnerable.

- Influence of industrial zones: The sensitive index of agricultural production activities for industrial zones is built from separating the information layer of the industrial zones status of the status map of using land. Calculating the distance with the largest value of $25 \mathrm{~km}$, the meaning of this indicator indicates that agricultural production activities which are close to industrial zone are more sensitive and vulnerable.

- Dependence level of the community: Criteria for labor of agriculture, forestry and fishery shows dependence on affected areas, the number of laborers/total population of localities reflects the basic economy depending on that locality for agriculture. The labour ratio of agriculture, forestry and fishery/total population is determined basing on survey data of the General Statistics Office following each commune. The rate is lower and lower showing the level of community dependence on agricultural production activity is greater and greater, the more sensitive and vulnerable it is.

\subsubsection{Variables of the Exposure Index (E) (Exposure)}

Rising sea level and the temperature change are the two main indicators of the climate change. IPCC organization has demonstrated that rising temperature leads to the rising sea level. Therefore, two main indicators are taken for vulnerability assessment.

- Rising sea level to 2100: The rising sea level index is based on the climate change scenario developed and announced by the MONRE, 2016. Data on using rising sea level by drama version RCP 4.5 is calculated to 2100 is $53 \mathrm{~cm}$ 
(32 - 75) for Thua Thien Hue area. Combining with the digital elevation model DEM allows determining which areas will flood until 2100 (MONRE, 2016).

- Temperature change to 2100: In 2100, in Thua Thien Hue under RCP 4.5 scenario, the temperature increase level at different locations of the region can be from $1.3^{\circ} \mathrm{C} \div 2.7^{\circ} \mathrm{C}$ (stage 2080 - 2099); The popular increase is $1.9^{\circ} \mathrm{C}$ (MONRE, 2016).

\subsubsection{Adaptable Index Variables (AC) (Adaptive Capacity)}

- Slope: Slope index is built from DEM elevation model, meaning of this indicator refers to agricultural production activities in areas with lower slopes, the higher the adaptability they are.

- Morphology: Morphological index is determined by the steps: calculating the area and perimeter of agricultural production activities, dividing the area for pi (3.14) and taking the square root to determine the radius of the figure The standard round corresponds to the area of agricultural production, then computes the circumference of the circle corresponding to the standard radius; taking the perimeter of agricultural production divided by the circumference of the circle. The larger this indicator shows the longer the form of agricultural production, the more vulnerable it is.

\subsection{Determining Weight and Calculating Vulnerability Index Values}

\subsubsection{Determine the Weight}

Applying the Delphi method in determining the weight of variables. Experts answer questions through two or more rounds. After each round, the questioner provides a weighted version of anonymous variables from experts from the previous rounds as well as the reasons they provided for their weights. Therefore, experts are encouraged to modify their weights earlier and after consulting the replies's ideas of other members in their tables. In this process the range of answers will decrease and will converge towards the "correct" answer. Finally, this process stops before determining a stop criterion (eg the number of rounds, the outcome of the consensus, the stability of the results) and the score average of the final rounds of weighting in determining the weight of variables.

Evaluating weights according to expert's opinion. Weight calculation results are determined according to the formula:

$$
\frac{X_{i}}{\sum_{i=1}^{n} X_{i}}
$$

Inside:

$X_{i}$ : Weight of the index $(i=1 ; 2 \ldots n)$

Example: Weight of traffic access: $3 /(3+6+5+6)=0.15$

Table 2 shows that through Delphi method has determined high-weighted indicators such as morphology (0.55), slope index (0.45), sea level rise up to 2100 , 
Table 2. Weight of indicators.

\begin{tabular}{cccc}
\hline TT & Index & Weighting & Calculates weight \\
\hline I & Sensitive index S (Sensitivity) & 3 & 0.3 \\
1 & Traffic access index & 3 & 0.15 \\
2 & Influence of residential areas & 6 & 0.3 \\
3 & Influence of industrial zones & 5 & 0.25 \\
4 & Dependence level of the community & 6 & 0.3 \\
II & Exposure index (Exposure) & 4 & 0.4 \\
5 & Sea level rises until 2050 & 4 & 0.5 \\
6 & Temperature change to 2050 & 4 & 0.5 \\
III & AC adaptability (Adaptive capacity) & 3 & 0.3 \\
7 & Slope & 5 & 0.45 \\
8 & Shape & 6 & 0.55 \\
\hline
\end{tabular}

temperature change to $2100(0.5)$, the level of influence of residential areas (0.3), the level of community dependence (0.3).

\subsubsection{Key Indicators (S, E, AC)}

The results of the main indicators are determined by the formula (World Wide Fund for Nature, WWF, 2013a):

$$
\text { Key indicators }=\frac{\sum_{i=1}^{n} a_{i} A_{i}}{n}
$$

Inside:

$a_{i}$ is the calculated $i^{\text {th }}$ weight of sub-indices.

$A_{i}$ is the value of the secondary index $i$ has normalized

$n$ : Total number of sub-indices

Example: Adaptability index (AC):

$((0.45 \times$ normalized slope value $)+(0.55 \times$ normalized morphological values $)) / 2$

\section{Study Results and Discussion}

\subsection{Establishing a Sensitive Index Map, Exposure Index and Adaptability Capacity}

Through Figure 2 and Table 3 showing: Sensitive index includes 5 indicators to indicate the index of access to traffic, the impact of residential areas, the impact of industrial zones, the level of dependence of the community. Very high sensitivity index accounts for $55.09 \%$ of the study area, including Dien Mon, Dien Hoa, Quang Ngan, Quang Cong, Phu Dien, Vinh Xuan, Vinh An, Vinh My and Vinh Hai communes. High sensitivity index accounted for $29.66 \%$ of Phong Binh, Quang Phuoc, Quang An and Vinh Phu communes; the low level accounts for $1.75 \%$ and very low level accounts for $0.70 \%$. As can be seen in the study area, there are $97.55 \%$ of the study area's area of sensitive index with average level up. 
Table 3. Area and rate of sensitivity index (S) of agricultural production activities in the coastal area of Thua Thien Hue province.

\begin{tabular}{cccc}
\hline TT & The level of vulnerability & Area (ha) & Rate (\%) \\
\hline 1 & Very low & 379.08 & 0.70 \\
2 & Low & 953.26 & 1.75 \\
3 & Medium & 6970.8 & 12.80 \\
4 & High & $16,151.22$ & 29.66 \\
5 & Very high & $30,001.39$ & 55.09 \\
& Total & $\mathbf{5 4 , 4 5 5 . 7 5}$ & 100 \\
\hline
\end{tabular}

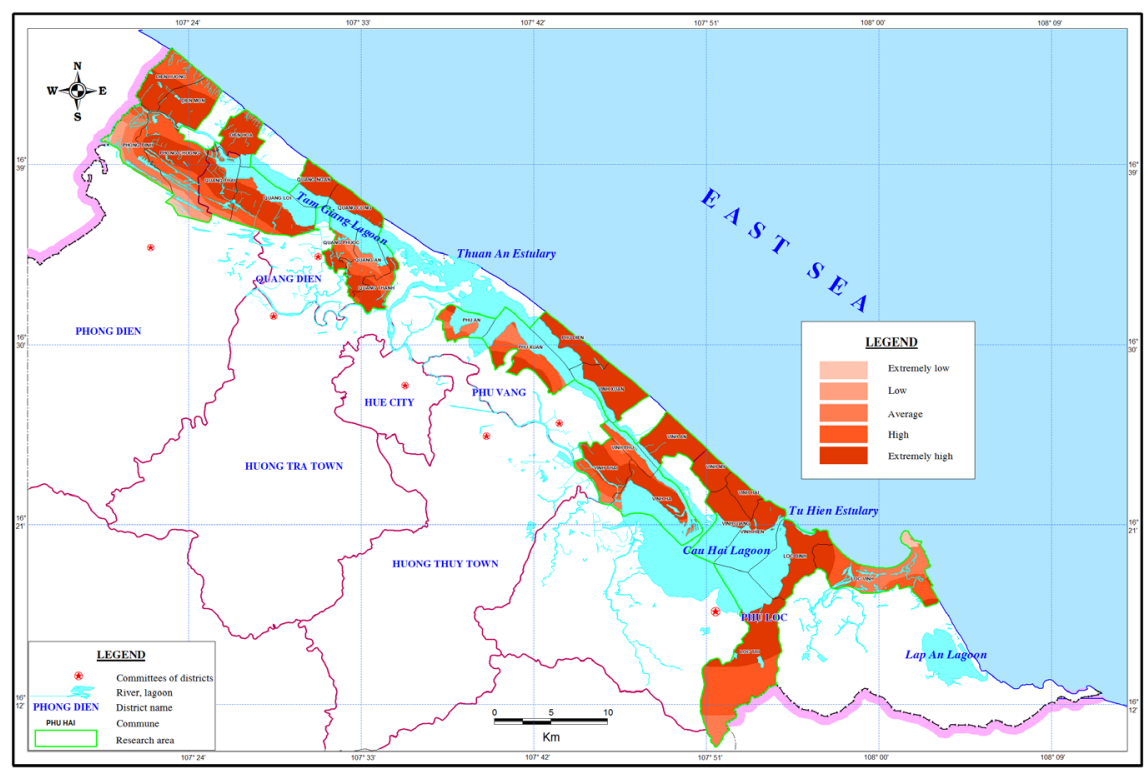

Figure 2. Sensitive index (S) synthesizing of agricultural production activities in the coastal area of Thua Thien Hue province.

This alarms that agricultural activity in the study area is highly sensitive to factors such as traffic, residential areas, industrial zones and communities.

Through Figure 3 and Table 4 showing: Exposure index includes 2 indicators for sea level rise to 2100 and temperature change to 2100 . In the study area, the main exposure index is at the average level of $52.89 \%$, the high level accounts for 27.42\%, mainly in Phong Binh, Phong Chuong, Quang Thai, Quang Phuoc, Quang An and Quang Thanh communes; the very high level accounts for 12.53\% of Dien Huong, Dien Mon and Quang Ngan communes. Thus, it can be seen that, through two factors of the rising sea level and the temperature change, the Northern and Northeastern regions of the study area have very high exposure index, this is because this area has the lowest elevation and the high temperature fluctuation in the whole coastal area of Thua Thien Hue.

Through Figure 4 and Table 5 showing: Adaptability capacity index includes 2 indicators for slope and morphology. In the study area, the main exposure index at the average level accounted for $70.17 \%$, the high level accounts for $10.4 \%$ of 
Table 4. Area and rate of exposure index (E) of agricultural production activities in the coastal area of Thua Thien Hue province.

\begin{tabular}{cccc}
\hline TT & The level of vulnerability & Area (ha) & Rate (\%) \\
\hline 1 & Very low & 755.78 & 1.39 \\
2 & Low & 3141.33 & 5.77 \\
3 & Medium & $28,803.93$ & 52.89 \\
4 & High & $14,932.6$ & 27.42 \\
5 & Very high & 6822.11 & 12.53 \\
& Total & $54,455.75$ & 100 \\
\hline
\end{tabular}

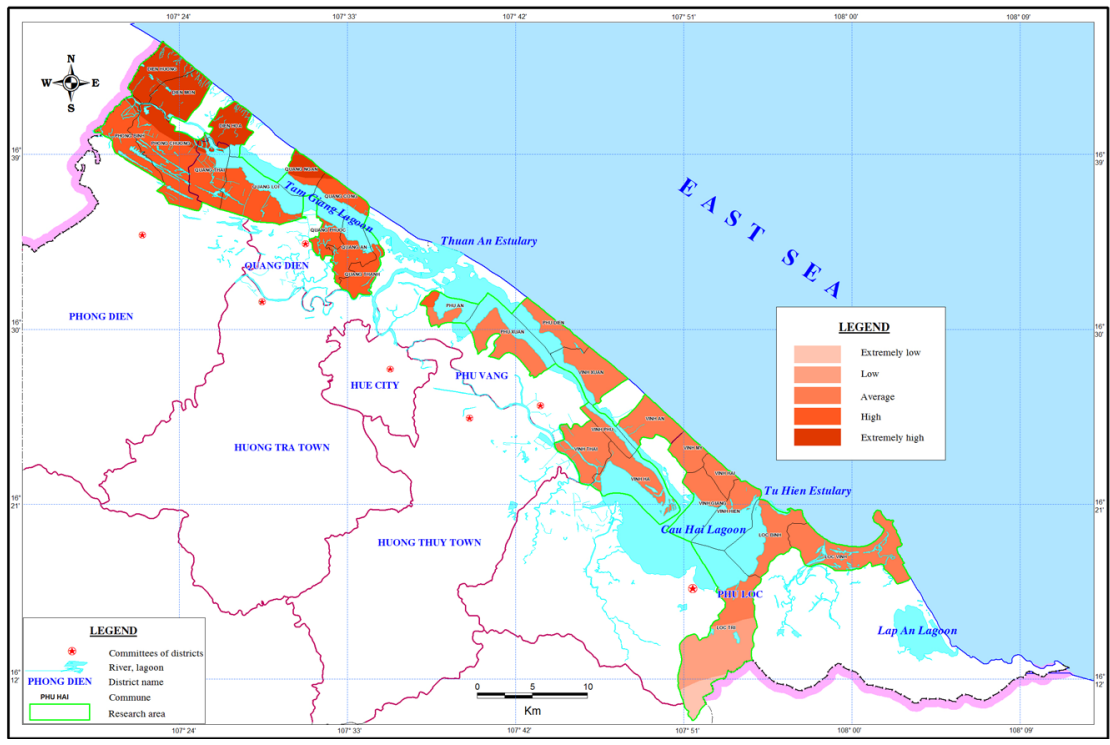

Figure 3. Exposure index (E) synthesizing of agricultural production activities in the coastal area of Thua Thien Hue province.

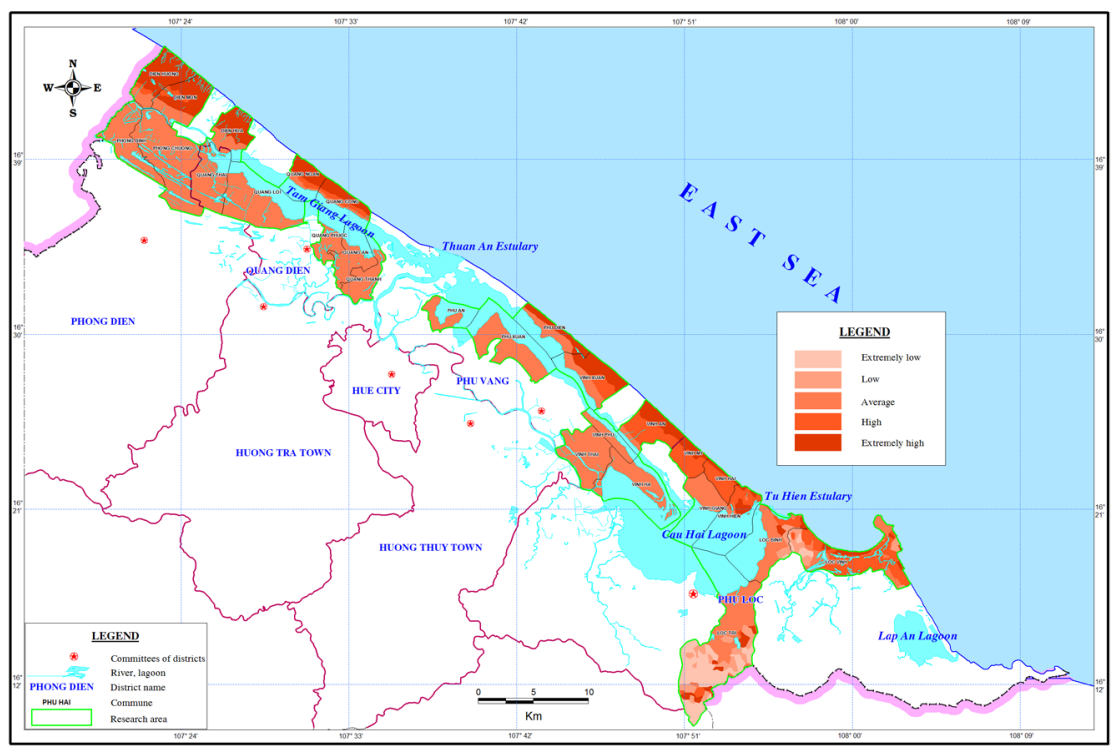

Figure 4. Integrated adaptability capacity index (AC) of agricultural production activities in the coastal area of Thua Thien Hue province. 
Table 5. Area and rate of adaptive capacity index (AC) of agricultural production activities in the coastal area of Thua Thien Hue province.

\begin{tabular}{cccc}
\hline TT & The level of vulnerability & Area (ha) & Rate (\%) \\
\hline 1 & Very low & 2108.74 & 3.87 \\
2 & Low & 1409.38 & 2.59 \\
3 & Medium & $38,213.08$ & 70.17 \\
4 & High & 5521.35 & 10.14 \\
5 & Very high & 7203.2 & 13.23 \\
& Total & $\mathbf{5 4 , 4 5 5 . 7 5}$ & $\mathbf{1 0 0}$ \\
\hline
\end{tabular}

the study areas in Vinh Xuan, Vinh An, Vinh My and Vinh Hai communes; the very high level accounts for $13.23 \%$ of the communes of Dien Huong, Dien Mon, Dien Hoa, Quang Ngan and Quang Cong; the low and very low level occupies very small areas, corresponding to $2.59 \%$ and $3.87 \%$. This is because the topography of the coastal area of Thua Thien Hue is mainly sand dunes and small coastal plains, so the adaptation index is not high.

\subsection{Establish Vulnerability Map}

Formula to apply vulnerability index (World Wide Fund for Nature, WWF, 2013a):

$$
\mathrm{V}=(\mathrm{E}+\mathrm{S}+\mathrm{IAC}) / 3
$$

In which: $\mathrm{IAC}=100-\mathrm{AC}$

$\mathrm{S}$ : The higher the sensitivity, the greater ( $\mathrm{S}$ is as low as possible)

$\mathrm{E}$ : The higher the level of impact the stronger (the lower the $\mathrm{E}$ the better)

AC: The higher the adaptive capacity, the better (AC higher is better)

In the case of the sub-indices of $\mathrm{S}, \mathrm{E}, \mathrm{AC}$ contrary to the above criterion, the value is inverse by the formula: Id = 1-I (Id: inverse index; I is the index)

Through Table 6 and Figure 5, there are 4506.07 ha accounting for $8.27 \%$ of the area of agricultural production activities in the coastal area of Thua Thien Hue province has the high vulnerability risk, concentrated in Dien Huong, Dien Mon, Dien Loc, Dien Hoa, Quang Ngan and Quang Cong communes. The level of high vulnerability is $32,575.37$ hectares, equivalent to $59.82 \%$ of Phong Chuong, Quang Thai, Quang Phuoc, Quang Thanh, Phu Dien, Vinh Xuan, Loc Dinh and Loc Tri communes. The average vulnerability level accounted for $15,286.49$ hectares, equivalent to $28.07 \%$. Very low vulnerability level accounts for 352.18 hectares, equivalent to $0.65 \%$ of Loc Tri communes. Thus, the area with a high vulnerability level accounts for $68.09 \%$ of the total area of the study area. This poses a huge problem for agricultural production in the study area, when the majority of the region has a high level of vulnerability while the main economic activity of the residents is agricultural production. Since then, there should be appropriate changes and solutions to highly adapt to climate change in agricultural activities in coastal areas of Thua Thien Hue province. 
Table 6. Area and rate of vulnerability of agricultural production activities in coastal area of Thua Thien Hue province.

\begin{tabular}{cccc}
\hline TT & The level of vulnerability & Area (ha) & Rate (\%) \\
\hline 1 & Very low & 352.18 & 0.65 \\
2 & Low & 1735.64 & 3.19 \\
3 & Medium & $15,286.49$ & 28.07 \\
4 & High & $32,575.37$ & 59.82 \\
5 & Very high & 4506.07 & 8.27 \\
& Total & $\mathbf{5 4 , 4 5 5 . 7 5}$ & 100 \\
\hline
\end{tabular}

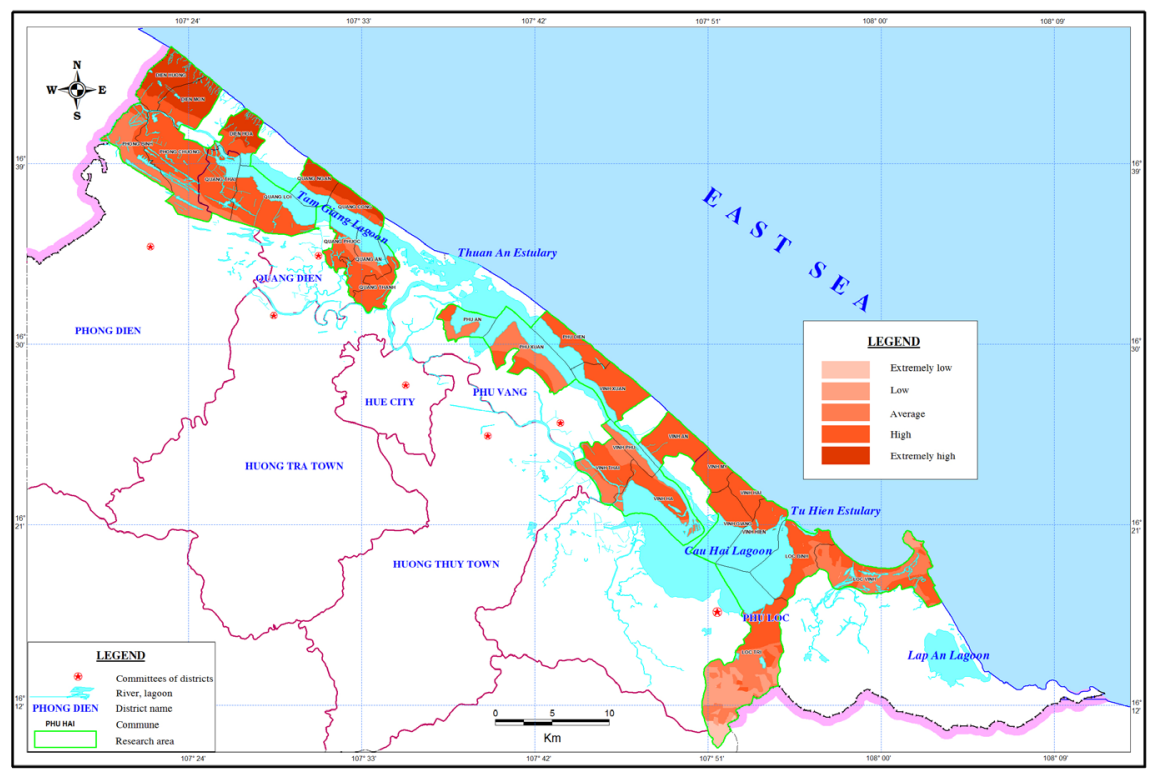

Figure 5. Map of vulnerability (V) of agricultural production activities in coastal area of Thua Thien Hue province.

\section{Conclusion}

Assessing the vulnerability level of agricultural production activities in the coastal area of Thua Thien Hue province, with the synthetic use of research methods, especially the method of bringing all quantities, is evaluated to be on the same unit, through the identification of variables and the entering calculation and evaluation of vulnerability level based on the impacts and effects of natural and socio-economic factors. Indicators are included in the vulnerability level assessment including sensitivity index (S) (including 4 sub-indicators which are indicators of the traffic access; impacts of residential areas; impacts of industrial zones, level of community dependence), exposure index (E) (including 2 sub-indices of the sea level rise to 2100; the temperature change to 2100), the adaptability capacity index (AC) (including 2 sub-indicators are slope, morphology). The analysis, evaluation and integration with GIS have shown the vulnerability of agricultural production activities in the coastal area of Thua Thien Hue following the very low vulnerability level accounting for 352.18 ha, 
equivalent to $0.65 \%$; the low vulnerability level accounting for 1735.64 hectares, equivalent to 3.19\%; the average vulnerability level accounting for $15,286.49$ hectares, equivalent to $28.07 \%$; and high vulnerability level accounting for 32,575.37 hectares, equivalent to $59.82 \%$ and very high vulnerability level accounting for 4506.07 hectares, equivalent to $8.27 \%$ of the total area of the study area.

\section{Conflicts of Interest}

The authors declare no conflict of interest.

\section{References}

Allison, E. H., Perry, A. L., Badjeck, M. C., Adger, W. N., Brown, K., Conway, D., Halls, A. S., Pilling, G. M., Reynolds, J. D., Andrew, N. L., \& Dulvy, N. K. (2009). Climate Change and Fisheries: A Comparative Analysis of the Relative Vulnerability of 132 Countries. Fisheries, 10, 173-196. https://doi.org/10.1111/j.1467-2979.2008.00310.x

Balangue, T. O. (2013). Summary Report on Vulnerability Caused by Climate Change and Impact Assessment Tools. Philippines: Climate Change Committee.

Blaikie, P., Cannon, T., Davis, I., \& Wisner, B. (1994). At Risk: Natural Hazards, People's Vulnerability, and Disasters. London: Routledge.

Carg, A. et al. (2007). Handbook of Current and Next Generation Vulnerabilities and Vulnerability Assessment Tool. New York: Routledge.

Cutter, S. L. (1996). Vulnerability to Environmental Hazards. Progress in Human Geography, 20, 529-539. https://doi.org/10.1177/030913259602000407

Forsyth, T. (2004). Critical Political Ecology: The Politics of Environmental Science. London: Routledge. https://doi.org/10.4324/9780203017562

ICEM (2015). Assessment of Vulnerability and Adaptation Planning of the Construction Industry in Urban Areas in the Mekong Basin ADB and Nordic Development Fund. Hanoi.

IPCC (Intergovernmental Panel on Climate Change) (2007). Fourth Assessment Report: Working Group II Report "Impacts, Adaptation and Vulnerability".

Meynell, P. J., Thongsavath, O., Xeuasing, K., Vannalath, V., \& Glémet, R. (2014). Assessment of the Vulnerability of Beung Kiat Ngong Ramsar Site, Lao PDR (127 p.). Vientiane: IUCN.

MONRE (Ministry of Natural Resources and Environment of Vietnam) (2009). Scenario of Climate Change and Sea Level Rise for Vietnam. Ha Noi: Environment-Resources Publisher and Viet Nam map.

MONRE (Ministry of Natural Resources and Environment of Vietnam) (2012). Scenario of Climate Change and Sea Level Rise for Vietnam. Ha Noi: Environment-Resources Publisher and Viet Nam map.

MONRE (Ministry of Natural Resources and Environment of Vietnam) (2016). Scenario of Climate Change and Sea Level Rise for Vietnam. Ha Noi: Environment-Resources Publisher and Viet nam map.

Morgan, C. L. (2011). Assessment of Vulnerability Status: An Overview of Approaches. Gland: IUCN

Ngu, N. D. (2008). Climate Change. Ha Noi: Science and Technology Publishing House.

Nhuan, M. T. (2002). Research and Evaluate the Vulnerability of the South Central Coast Region as a Scientific Basis for Mitigating Disasters and Sustainable Land Use Plan- 
ning. Ha Noi: Ministry of Natural Resources and Environment.

Nhuan, M. T. (2011). Investigating and Assessing the Extent of Vulnerability to Vietnam's Marine Resources and Environment and Meteorological Conditions; Forecasting Natural Disasters and Environmental Pollution in Sea Areas. Ha Noi: Ministry of Natural Resources and Environment.

O'Keefe, P., Westgate, K., \& Wisner, B. (1976). Taking the Naturalness Out of Natural Disasters. Nature, 260, 566-567. https://doi.org/10.1038/260566a0

Peet, R., \& Watts, M. (2004). Liberation Ecologies: Environment, Development, Social Movements (2nd ed.). London: Routledge. https://doi.org/10.4324/9780203235096

PROVIA (2013). Guidelines for Assessing Vulnerability, Adaptation and Adaptation Capacity (p. 198). Nairobi: Consultation Materials, United Nations Environment Program.

Rizvi, A. R., van Riel, K., \& Zakowski, E. (2014). Summary Report on Tools and Methodologies Assessing Vulnerability and Adaptation Capacity to Climate Change. IUCN EbA Knowledge Series, Working Paper.

Schipper, L., Liu, W., Krawanchid, D., \& Chanthy, S. (2010). Overview of MRC Adaptation Methods and Tools. Technical Report No. 34, Vientiane: Mekong River Commission.

Son, N. T., \& Van, C. T. (2012). Methods of Vulnerability Assessment-Theory and Practice: Part 1: Applicability in Flood Vulnerability Assessment in Central Vietnam. Scientific Journal of Hanoi National University: Natural Science and Technology, 28, 115-122.

Thua Thien Hue Statistical Office (2017). Thua Thien Hue Statistical Yearbook in 2017. Thua Thien Hue: Statistical Publishing House.

Turner, B. L. I., Kasperson, R. E., Matson, P. A., McCarthy, J. J, Corell, R. W., Christensen, L., Eckley, N., Kasperson, J. X., Luers, A., Martello, M. L., Polsky, C., Pulsipher, A., \& Schiller, A. (2003). A Framework for Vulnerability Analysis in Sustainability Science. Proceedings: National Academy of Sciences of the United States of America, 100, 8074-8079. https://doi.org/10.1073/pnas.1231335100

UNFCCC (2008). The Report Summarizes the Methods and Tools for Assessing Impacts, Vulnerabilities and Capacity to Adapt to Climate Change. UNFCCC Secretariat.

USAID (2013). Mekong ARCC Climate Change Impact and Adaptation Study. https://www.usaid.gov/asia-regional/documents/usaid-mekong-climate-change-studymain-report-2013

Walton, M., Bebbington, A. J., Dani, A. A. \& de Haan, A. (2008). Institutional Pathways to Equity: Addressing Inequality Traps. Washington DC: The World Bank. https://doi.org/10.1596/978-0-8213-7013-1

White, G. F., \& Haas, J. E. (1975). Assessment of Research on Natural Hazards. Cambridge, MA: MIT Press.

Wisner, B., Blaikie, P., Cannon, T., \& Davis, I. (2004). At Risk: Natural Hazards, People's Vulnerability and Disasters (2nd Ed.). New York: Routledge.

World Bank (2010). Economics of Adaptation to Climate Change in Vietnam's Aquaculture Sector.

http://documents.worldbank.org/curated/en/563491468149078334/Vietnam-Economic s-of-adaptation-to-climate-change

WWF (World Wide Fund for Nature) (2012). Rapid Assessment of Vulnerability and Adaptability to Climate Change in Three Coastal Districts, Ben Tre Province. Hanoi: WWF. 
WWF (World Wide Fund for Nature) (2013a). Assessing the Level of Vulnerability to Climate Change of Ecosystems in Vietnam. Hanoi: WWF.

WWF (World Wide Fund for Nature) (2013b). Integrating Ecosystem Access in Adapting to Changing Climate into Biodiversity Conservation Planning in Vietnam. Hanoi: WWF.

Zimmerer, K. S., \& Bassett, T. J. (2003). Political Ecology: An Integrative Approach to Geography and Environment-Development Studies. New York: Guilford Press. 